neuromuscular transmission. Neurology (NY) 1981;31:265-71.

- Lundh H. Therapeutic applications of aminopyridines in diseases of neuromuscular transmission. In: Lechat $P$, Thesleff $S$, Bowman WC, eds. Aminopyridines and Similarly Acting Drugs. Advances in the Biosciences Vol 35. Oxford: Pergamon Press, 1982:287-96.

' Molgo J, Lundh H, Thesleff S. Potency of 3,4diaminopyridine and 4-aminopyridine on mammalian neuromuscular transmission and the effect of pH changes. Europ J Pharmacol 1980;61:25-34.

${ }^{10}$ Lechat P, Deysson G, Lemeignan M, Adolphe M. Toxicité aigue composeé de quelques aminopyridines in vivo (Souris) et in vitro (cultures cellulaires). Ann Pharmac Fr 1968;26:345-49.

Accepted 10 February 1983

\section{Sustained levodopa therapy in tardive dyskinesia}

Sir: The pathophysiology of tardive dyskinesias is still poorly understood, but striatal post-synaptic dopamine receptor hypersensitivity may be implicated.' ${ }^{\prime}$ Permanent discontinuation of the offending neuroleptic offers the best hope of relief, but the patients' mental state often precludes this. Tetrabenazine is the most effective drug treatment, but side-effects including sedation, depression, Parkinson's syndrome and akathisia are common. The longterm administration of levodopa to rodents has recently been shown to attenuate the behavioural and biochemical features of dopaminergic hypersensitivity. ${ }^{23}$ Promising results have also been reported in tardive dyskinesia giving sustained levodopa treatment ${ }^{2}$ or small doses of dopamine receptor agonists. ${ }^{4}$ In view of these findings we have been encouraged to extend this approach to the treatment of patients with irreversible, persistent dyskinesias no longer receiving neurolpetics.

Seven patients (six female, one male) with moderate or severe tardive dyskinesia agreed to participate. Their mean age was 69 years (range 53-93) and the mean duration of involuntary movements was 7 years (range 3-12). Neuroleptics had been given for a mean period of 9.2 years (range 3-30) for schizophrenia, save for three with chronic dyspepsia, agoraphobia and depression respectively. Their conditions were static and their movement disorders comprised a bucco-linguo-masticatory syndrome in seven, additional limb chorea in five and torticollis in one. Two had coexistent akathisia, but none had Parkin- son's disease. With one exception all had discontinued neuroleptics for at least one year (mean 4 yr) before the trial. Baseline clinical assessments were made by two independent observers using the AIM scale $^{\mathbf{s}}$ and dyskinesia was -recorded simultaneously on video tape. Levodopa $300 \mathrm{mg}$ daily in combination with benserazide was then gradually introduced (Madopar 125, 1 capsule 8 hourly) and the patients assessed at 14 day intervals by the same observers. After a minimum of 12 weeks sustained therapy, patients were re-filmed and the levodopa then discontinued abruptly. Follow-up observation continued for six months with AIM scale scoring.

An initial aggravation of the dyskinesias was seen in one patient following levodopa introduction, but otherwise no significant changes in dyskinesia severity occurred at any stage of the trial.

These disappointing results do not compare favourably with those obtained by Bjørndal and colleagues who reported modest improvement in drug-free patients following one month's levodopa therapy. ${ }^{6}$ Benefit has also been claimed with chronic levodopa in patients still receiving neuroleptics ${ }^{7}$ or in those who have just stopped them. ${ }^{8}$ Casey et al,${ }^{9}$ however, using very large doses of levodopa in combination with benserozide for treatment periods of 8 weeks failed to produce benefit in five neuroleptic treated schizophronics with tardive dyskinesia. In contrast to other studies we also failed to demonstrate an initial increase in dyskinesia following levodopa introduction.? Further studies using dopamine receptor agonists and large doses of levodopa in this refractory group of incapacities are now under way.

RJ HARDIE

AJ LEES

GM STERN

Department of Neurology, University College Hospital, London WC1 6AU, UK

\section{References}

' Marsden CD, Jenner P. The pathophysiology of extrapyramidal side-effects of neuroleptic drugs. Psychol Med 1980;10:55-72.

${ }^{2}$ Alpert M, Friedhoff AJ. Receptor sensitivity modification in the treatment of tardive dyskinesia. Clin Pharmacol Ther 1976;19:103.

${ }^{3}$ Ezrin-Waters C, Seaman P. L-dopa reversal of hyperdopaminergic behaviour. Life Sci 1978;22:1027-32.

4 Carroll BJ, Curtis GC, Kokmen E. Paradoxical response to dopamine agonists in tardive dyskinesia. Am J Psychiat 1977;134;785-9.

s Abnormal involuntary movement scale. In: Guy W, ed. ECDEU Assessment Manual.
Rockville: US Department of Health Education and Welfare. 1976;534-7.

- Bjørndal N, Casey D, Gerlach J. In: Cattabeni F. et al eds, Longterm effects of Neuroleptics. Adv Biochem Psychopharm Vol. 24. New York: Raven Press, 1980;541-5.

' Alpert M, Friedhoff AJ, Diamond F. Use of dopamine receptor agonists to reduce dopamine receptor number in tardive dyskinesia. In: Fahn S, Calne DB, Shoulson I eds Experimental Therapeutics of Movements Disorders. New York: Raven Press, 1983:253-8.

Shoulson I. Carbidopa/levodopa therapy of co-existent drug-induced Parkinsonism and tardive dyskinesia. In: Fahn S, Calne DB, Shoulson I eds Experimental Therapeutics of Movement Disorders. New York: Raven Press, 1983:259-66.

- Casey DE, Gerlach J, Bjørndal N. Levodopa and receptor sensitivity modification in tardine dyskinesia Psychopharmacology 1982;78:89-92.

\section{Giant aneurysm of the petrous portion of} the carotid artery.

Sir: Aneurysms of the internal carotid artery extracranially are rare; those arising from the petrous segment are particulary unusual. A survey of the literature showed approximately 30 reported cases. ${ }^{1-19}$

A 28-year-old woman had been complaining of severe left ear pain, tinnitus and hearing loss for approximately six months. The pain was continuous and irradiated towards the face, the retromastoid region and sometimes down to her neck. At ENT consultation a vascular mass was found in the left middle ear. An attempted biopsy resulted in massive bleeding controlled by packing the ear. She was then referred to the neurosurgical department with the diagnosis of glomus tumour. Besides a left sensorineural deafness, neurological examination was normal. Both carotid pulsates normally and no bruit was heard about the head and neck. Skull radiographs demonstrated a large area of bone erosion in the left petrous pyramid extending anteriorly into the sphenoid sinus. A sclerotic ring could be noticed around the lytic lesion, suggesting a chronic process. Left carotid arteriography revealed a large $(1.5 \times 2.5 \times 5 \mathrm{~cm}$.) aneurysm located in the petrous segment of the carotid artery projecting laterally into the middle ear, with normal intracranial arborisation. Right carotid arteriography with left carotid compression showed excellent cross filling of the left anterior cerebal and middle cerebral arteries, without aneurysm opacification. 


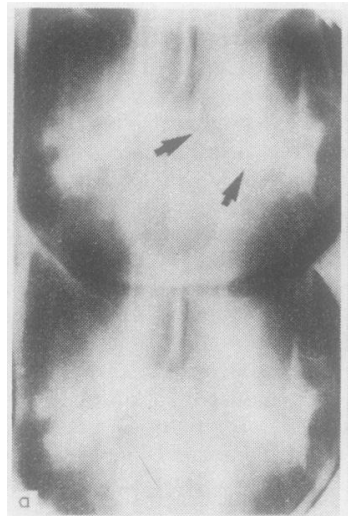

Fig (a) Mentovertex tomograph showing a large oval area of erosion with sclerois in the margins. (arrows) (b) Left anteroposterior common carotid subtraction angiography demonstrating a giant aneurysm in the petrous bone. (c) Left common carotid angiography, mentovertex view, showing the anterior extension of the aneurysm.

Under local anaesthesia the left common carotid artery first was clamped for 30 minutes without neurological deficits and then was double ligated. Recovery was uneventful and the patient was discharged pain free but still deaf.

Such aneurysms can present with spontaneous and repeated episodes of otorrhagia $^{37121718}$ or epistaxis via the Eustachian tube. ${ }^{1716}$ The Eustachian tube is located anteriorly and parallel to the horizontal portion of the carotid canal. In a microanatomic study Wayne et $a^{26}$ showed that the Eustachian tube was separated from the carotid artery by a thin layer of bone in $94 \%$ of the 50 cadavers examined and by mucosa only in the $6 \%$ remaining. In $56 \%$ the bone was very thin, measuring $0.1 \mathrm{~mm}$. to $0.3 \mathrm{~mm}$. the average thickness being $0.8 \mathrm{~mm}$. Busby et al ${ }^{16}$ in a pathological study showed an aneurysm that perforated the bone septa and ruptured into the Eustachian tube. Such bleeding episodes often are dramatic and transfusion of several units of blood are required to reverse the hypotension and anaemia. ${ }^{1371618}$ Death due to exsanguination occurred in Busby's case. ${ }^{16}$ Massive bleeding can also be the result of attempted biopsy for presumed glomus tumours.911-1319

When the aneurysm is located medially it may cause only a VIth nerve palsy, ${ }^{415}$ or a combination of deafness and paralysis of the abducens. ${ }^{16}$ Guirguis and Tadros ${ }^{5}$ reported a patient with deafness and involvement of the 6 th, 7 th, 9th, 10th cranial nerves. Gupta and colleagues ${ }^{17}$ reported a 8-year-old girl with involvement of the 6 th, 7 th, 9 th, 10 th cranial nerves. Both Harrison et al, ${ }^{6}$ and Drake ${ }^{15}$ presented cases with disfunction of the trigeminal nerve alone. Ear pain and deafness as in our patient was reported by Allen.'

Several causes of aneurysms of the petrous portion of the carotid artery have been reported. Head trauma is the most common.47101419 Congenital aneurysms were reported by several authors. ${ }^{5611121518}$ Others $^{318}$ suggested that chronic middle ear infection may lead to aneurysm formation due to destruction of the external layers of the carotid artery. One case occurred after mastoidectomy. ${ }^{2}$ In the present case there is no history of head trauma, temporal bone surgery or otitis. Probably the aneurysm was congenital.

Most of the reports cases were successfully treated by common carotid liga-

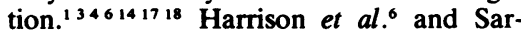
war $^{15}$ reported gradual occlusion. Others preferred a one step ligation. ${ }^{1341819}$ Acute or gradual internal carotid ligation with an extracranial bypass procedure also has been suggested by Gelber \& Sundt ${ }^{21}$ and Drake. ${ }^{16}$

We are grateful to Dan Marchesin Ph.D for editorial assistance.

JC LYNCH

MA AMARAL

A PAREIRA

Centro Médico Richet

José Carlos Lynch

Rua Sorocaba, 477/602 - zip code 22271

Botafogo - Rio de Janeiro

Brazil
References

' Pierini AA, Agra A. Epistaxis como signo de hemorragia de la carotida intera en su porcion timpanica. Prensa Med Argent 1954;41:945-8.

${ }^{2}$ Barret JH, Lawrence VL. Aneurysm of the internal carotid artery as a complication of mastoidectony. Arch Otolaryngol 1960; 72:366-368.

${ }^{3}$ Ehni G, Barret JH. Hemorrhage from the ear $\equiv$ due to an aneurysm of the internal carotid. New Engl J Med 1960;262:1323-5.

4 Pecker J, Hoel J, Javalet A, Fournier H. Paralysie du moteur oculaire externe par aneurysme intra-petreux traumatique de la cartoid interne. Presse Med 1960; 68:1023-5.

${ }^{5}$ Guirguis S, Tadros FW. An internal carotid aneurysm in the petrous temporal bone. $J$ Neurol Neurosurg Psychiatry 1961;24: 84-85.

' Harrison TH, Odom GL, Kunkle EC. Internal carotid aneurysm arising in carotid canal. Arch Neurol 1963;68:328-31.

7 Yarborough WL, Harrill JA, Alexander E, Jr. Traumatic internal carotid aneurysm rup- o ture into sphenoid sinus with angiographic demonstration. Laryngoscope 1963; 73:1313-25.

- Wemple JB, Smith GW. Extracranial carotid aneurysm. Report of four cases. $J$ Neurosurg 1966;24:667-71.

- Allen GW. Angiography in otolaryngology. Laryngoscope 1967;77:1909-60.

"Busby DR, Slemmons DH, Miller TF. Fat迎 epistaxis via carotid aneurysm and Eus= tachian tube. Arch Otolaryngol 1962 87:295-8.

"Conley J, Hildyard V. Aneurysm of the internal carotid artery presenting in the middle ear. Arch Otolaryngol 1969;90:35-8.

${ }^{12}$ Stallings JO, McCabe BF. Congenital middle ear aneurysm of internal carotid. Arch Otolaryngol 1969;90:39-43.

${ }^{13}$ Anderson RD, Liebeskind A, Schecter MM, Zingesser LH. Aneurysms of the internal carotid artery in the carotid canal of the petrous temporal bone. Radiology 1972;102:639-42.

14 Teal JS, Bergeron RT, Rumbaugh CL, Segall HD. Aneurysm of the petrous or cavernous portions of the internal carotid artery associated with nonpenetrating head trauma. $J$ Neurosurg 1973;38:568-74.

is Sarwar M. Abducens nerve paralysis due to $\exists$ giant aneurysm in the medial carotid canal. J Neurosurg 1977;46:121-3.

${ }^{16}$ Drake CG. Giant intracranial aneurysms: Experience with surgical treatment in 174 patients. Clin Neurosurg 1979;26:12-95.

" Gupta SK, Gupta OP, Singh MM, Varma DN,Kesharwani $R$. Giant aneurysm of the internal carotid artery in the carotid canal. $J \mathrm{~N}$ Laryngol Otol 1979;93:299-305.

18 Holtzman RNN, Parisier SC. Acute spontaneous otorrhagia resulting from a ruptured petrous carotid aneurysm. J Neurosurg 1979;51:258-61. 
19 Thomas JN, McCormick M. Aneurysms of the internal carotid artery: Otolaryngological Manifestations. J Laryngol Otol 1979; 93:383-92.

26 Wayne PS, Pait GT, Rhoton AL. Microsurgical exposure of the petrous portion of the carotid artery. $J$ Neurosurg 1977;47:71326.

21 Gelber BR, Sundt TM. Treatment of intracavernous and giant carotid aneurysms by combined internal carotid ligation and extra - to intracranial bypass. J Neurosurg 1980;52:1-10.

Accepted 18 December 1982

Sudden hearing loss and facial palsy at the contralateral side following acoustic tumour removal

Sir: We wish to report an unusual and unexpected complication following the removal of an acoustic neuroma.

A 37-year-old woman was admitted for excision of a large right sided acoustic neuroma. Computed tomographic (CT) scanning of the brain showed in addition to the cerebellopontine mass, three small right sided meningiomas, in the frontopolar, falcial and supratentorial regions, without any mass effect. The acoustic neuroma was completely removed through a suboccipital approach while the patient was in a left lateral recumbent position. After the operation, there was complete hearing loss on the right but preserved function of the facial nerve. The postoperative recovery was excellent. The patient received chloramphenicol and high doses of prednisolone. The second day after operation she was allowed to sit erect and suddenly developed complete deafness accompanied by vertigo and left sided peripheral facial palsy. Beside this, neurological examination disclosed horizontal nystagmus to the right and deviation to the left with the Romberg test. Audiometric testing showed a complete hearing loss on the right and an almost complete sensorineural hearing loss on the left. Brain stem auditory evoked responses were absent on both sides. The stapedius reflex was absent on the left. On electronystagmography a spontaneous nystagmus to the right was recorded and caloric testing revealed a marked diminished excitability of the left labyrinth. CT scanning of the brain, nine days after the operation, showed the operative changes and the three meningiomas, but no other abnormalities. Corticoid therapy was resumed for some days without any improvement.
During the following months there was no recovery of this left sided deficit.

The patient described here developed a sudden sensorineural hearing loss, loss of vestibular function and a peripheral facial paralysis on the non operated side, the second day after uncomplicated removal of an acoustic neuroma. This complication has to our knowledge not been reported previously. However, recently three cases of sudden contralateral hearing loss after operation in acoustic neuroma patients have been described.' In two of them, the hearing loss was of the perceptive type with the lesion situated respectively retrocochlear and cochlear, appearing the seventh and fourth day after the intervention. There were no other neurological signs. The deficit slowly improved, but the aetiology remained obscure. In the third case, the hearing loss resulted from a serious middle ear effusion. The first two cases show some similarity with our patient, except that they had no facial nerve involvement. The exact mechanism responsible for the event in our case could not be established. However, the lesion must be localised on both the left cochleovestibular nerves and/or inner ear and the left facial nerve. A possible explanation, in our opinion the most acceptable, is that there has been an occlusion of the left internal auditory artery. A postoperative shift of the brain stem to the right, possibly delayed by the presence of oedema at the operative site, could have been resulted in a stretching and subsequent thrombosis of this vessel. This theory is supported by the sudden onset of the deficit, and the fact that this artery supplies a part of both nerves and the inner ear. Occlusion of the internal auditory artery is indeed a well known cause of sudden deafness and loss of vestibular function, ${ }^{2}$ but it is generally not considered as a cause of peripheral facial jalsy. Nevertheless, the part of the facial nerve situated in the internal auditory canal is supplied by this artery. ${ }^{3}$ However, there exists a great variability in the vascularisation of this structures. Usually there is more than one internal auditory artery, ${ }^{4}$ and the facial nerve is for the most part supplied by branches of the occipital and middle meningeal arteries and by the anterior inferior cerebellar artery. ${ }^{3}$ Therefore, if the internal auditory artery (or arteries) is (are) occluded, the facial nerve function will be spared in most cases. Consequently, this vascular hypothesis offers also a possible explanation for the cases only affected by a sudden contralateral hearing loss following acoustic tumour removal. These cases are probably not restricted to the two patients mentioned above. Our case was but a variation of a possible complication of cerebellopontine mass removal that, although rare, merits further attention. A better understanding of these events could lead to preventive measures to avoid such a dramatic complication.

J DE KEYSER M BRUYLAND P DEMOL R KLAES

G EBINGER

Departments of Neurology and Otolaryngology,

Akademisch Ziekenhuis Vrije Universiteit Brussel, Brussels.

Department of Neurosurgery, Algemeen Ziekenhuis Middelheim, Antwerp, Belgium

\section{References}

' Clemis JD, Mastricola PG, Schuler-Vogler M. Sudden hearing loss in the contralateral ear in postoperative acoustic tumor: three case reports. Laryngoscope 1982;92:76-9.

${ }^{2}$ Mathog RH, Viscomi G. Otologic manifestations of retrocochlear disease. In: Paparella MM and Shumrick DA, eds. Otolaryngology Vol 2. Philadelphia: WB Saunders Company 1980:1912-3.

${ }^{3}$ Groves J. Facial paralysis. In: Balantyne J, Groves J, eds. Scotti-Brown's Diseases of the Ear, Nose and Throat Vol 2. London: Butterworths 1980:870.

4 Ouaknine GE. Microsurgical anatomy of the arterial loops in the pontocerebellar angle and the internal acoustic meatus. In: Samii $M$ and Jannetta PJ, eds. The Cranial Nerves. Heidelberg: Springer-Verslag 1981:378-90. 